\title{
$\alpha$-Tocopherol loaded thermosensitive polymer nanoparticles: preparation, in vitro release and antioxidant properties
}

\author{
Cirley Quintero', Ricardo Vera ${ }^{1}$ and Leon Dario Perez ${ }^{2 *}$ \\ ${ }^{1}$ Departamento de Química, Pontificia Universidad Javeriana, Bogotá, D.C., Colombia \\ ${ }^{2}$ Grupo de Macromoléculas, Departamento de Química, Universidad Nacional de Colombia - UNAL, \\ Bogotá, D.C., Colombia \\ *Idperezp@unal.edu.co
}

\begin{abstract}
$\alpha$-Tocopherol is the most bioavailable and active compound found in vitamin $\mathrm{E}$ with potential application in pharmaceutical, alimentary and cosmetic industries. However, its low solubility in aqueous medium and environmental instability limit its dosage. In this paper, we report the preparation of $\alpha$-tocopherol loaded nanoparticles (TOC-NP) based on amphiphilic thermosensitive triblock copolymers PNIPAM-b-PCL-b-PNIPAM. The nanoparticles exhibited a core - shell structure, were positively charged and presented average diameters below $300 \mathrm{~nm}$. TOC-NP presented controlled release of $\alpha$-tocopherol at room temperature along $140 \mathrm{~h}$, and exhibited antioxidant properties in aqueous medium.
\end{abstract}

Keywords: $\alpha$-tocopherol, polycaprolactone, thermosensitive nanoparticles, triblock copolymer.

\section{Introduction}

$\alpha$-tocopherol (TOC), the most studied and bioavailable component of vitamin E, presents antioxidant activity, its consumption is widely considered to help to reduce risk of many chronic diseases associated to oxidative stress ${ }^{[1]}$. Thus, TOC is a widely used component in functional food, cosmetic and pharmaceutical industries. However, the design of proper dosage forms is still challenging due to its hydrophobicity and well-known sensitivity to oxygen and light.

In order to overcome its environmental susceptibility, and improve its solubility in aqueous medium, encapsulation has been recently exploited by several authors ${ }^{[2-4]}$. The use of nanoparticles besides improving solubility in water, also provides controlled releasing. Some materials such as gliadin nanoparticles ${ }^{[5]}$, self-assembled nanoparticles of tocopheryl monoesters modified-chitosan conjugates ${ }^{[6]}$, and chitosan nanoparticles coated with zein ${ }^{[7]}$ have been reported.

Polymer nanoparticles (NP) have recently received great attention in the encapsulation and controlled release of bioactive substances ${ }^{[8]}$. They are obtained by the aggregation of water insoluble polymers in aqueous medium, assisted by different techniques such as solvent evaporation, salting-out, dialysis and supercritical fluids ${ }^{[9]}$. Nevertheless, these aggregates are in most of the cases colloidally unstable, and require the use of stabilizers such as surfactants and hydrophilic polymers which making their preparation a complex process dependent on many parameters such as stabilizer concentration, ionic strength, the co-solvent characteristics, and mixing speed.

Analogous to low molecular weight surfactants, amphiphilic block copolymers composed of hydrophilic and hydrophobic segments self-assemble in aqueous medium via hydrophobic association, which enables the preparation of $\mathrm{NP}^{[10,11]}$. The presence of hydrophobic domains confers the resulting nanoparticles the ability of encapsulating hydrophobic substances. On the other hand, the hydrophilic block besides conferring colloidal stability to the NP, can also lead the particles to exhibit stimuli sensitive responses. For example, there are several reports about polymer nanostructures containing PNIPAM which endows them thermosensitivity, since it exhibits a lower critical solution temperature at $32{ }^{\circ} \mathrm{C}^{[12]}$.

The implementation of technologies based in block copolymers is stimulated by advances in controlled radical polymerizations. Atom transference radical polymerization (ATRP) is one of the most versatile and powerful techniques that allows obtaining materials with controlled composition, and molecular weight and dispersity. The essential feature of ATRP is the equilibrium between a low concentration of active propagating species, and a larger number of dormant chains ended, via an inner sphere electron transfer process promoted by a transition metal complex. The main drawback of using ATRP is the removal of oxygen traces that requires tedious degasification process to avoid the catalyst deactivation. The development of Activator ReGenerated by Electron Transfer (ARGET) ATRP, which can be conducted in the presence of oxygen, enables the synthesis of novel structures such as bioconjugated materials and functional surfaces $^{[13]}$.

In the present work, we report the preparation and characterization of thermosensitive $\alpha$-Tocopherol-loaded polymer nanoparticles (TOC-NP). The nanostructures were obtained from triblock copolymers PNIPAM-b-PCL-bPNIPAM synthesized via ARGETATRP. Polycaprolactone (PCL), is a semicrystalline aliphatic polyester, considered as a biocompatible, and bioresorbable material with high permeability to drugs approved by the FDA for biomedical 
applications ${ }^{[14-17]}$. On the other hand, PNIPAM is the most widely used thermosensitive polymer, the proximity of its transition temperature to physiological values have encourage its application in the fabrication of several biomedical devices ${ }^{[18]}$.

\section{Materials and Methods}

\section{1 Materials}

N-Isopropylacrylamide (NIPAM, 98\%) was recrystallized from hexane, $\alpha, \omega$-dihydroxy-Poly( $\varepsilon$-caprolactone) of $M_{N}=10$ and $45 \mathrm{kDa}$ was purified by precipitation from a mixture of THF and methanol. 2-Bromoisobutyryl Bromide (BIBB, 98\%), triethylamine (>99\%), cupper(II) bromide $\left(\mathrm{CuBr}_{2}, 98 \%\right)$ N,N,N',N",N"-Pentamethyldiethylenetriamine (PMDETA, 99\%), anisole and $\alpha$-tocopherol were used without any additional purification. All the reagents including solvents (hexane, acetone, methanol and tetrahydrofuran) were supplied by Sigma - Aldrich.

\subsection{Synthesis procedures}

Synthesis of dibromide ended PCL: Br-PCL-Br was synthesized using a protocol previously published ${ }^{[19]}$. In a typical procedure for PCL Mn=10 KDa, $5 \mathrm{~g}$ of diol-ended PCL $(0.35 \mathrm{mmol})$ was dissolved in $50 \mathrm{~mL}$ of anhydrous dichloromethane with $500 \mu \mathrm{L}$ of triethylamine $(3.5 \mathrm{mmol})$ whereas stirring under argon atmosphere. After that, $431 \mu \mathrm{L}$ of $\mathrm{BIBB}(3.5 \mathrm{mmol})$ is added drop wise to the above-mentioned solution, previously cooled using an ice-water bath. The reaction mixture was stirred during $24 \mathrm{~h}$ at room temperature. The product was precipitated by the addition of an excess of methanol, recovered by filtration, and finally submitted to three precipitation cycles. The same procedure was used to modify PCL of $45 \mathrm{KDa}$.

Synthesis of PNIPAM-b-PCL-PNIPAM: A typical protocol for the synthesis of copolymer 18:88:18 via ARGET-ATRP of NIPAM using Br-PCL-Br $\left(\mathrm{M}_{\mathrm{n}}=10 \mathrm{kDa}\right)$ as macroinitiator, and $\mathrm{Cu}$ (II) $\mathrm{Br}_{2}$ / PMDETA was as follows: In a reaction vessel, $\mathrm{Br}-\mathrm{PCL}-\mathrm{Br}(0.5 \mathrm{~g}, 36 \mu \mathrm{mol})$ was dissolved in $5 \mathrm{~mL}$ of anisole to which NIPAM $(0.384 \mathrm{~g}, 3.4 \mathrm{mmol})$ and PMDETA (12.5 mg, $72 \mu \mathrm{mol})$ and $\mathrm{CuBr}_{2}(5.2 \mathrm{mg}, 36 \mu \mathrm{mol})$ were added. The system was purged with argon during $15 \mathrm{~min}$. Then, Tin(II) 2-ethylhexanoate $\left(\mathrm{Sn}(\mathrm{EH})_{2}\right)(72 \mathrm{mg}$, $180 \mu \mathrm{mol})$ was added, the system was degassed by $5 \mathrm{~min}$, and the polymerization reaction was allowed to proceed at $80{ }^{\circ} \mathrm{C}$ under argon atmosphere during $4 \mathrm{~h}$. The reaction product was passed through a column packed with basic alumina to eliminate cupper and tin residuals, and purified by three successive precipitations from a THF solution by the addition of methanol.

\subsection{Copolymers characterization}

${ }^{1} \mathrm{HNMR}$ spectra were collected in a Bruker Avance III spectrometer operated at $300 \mathrm{MHz}$. Samples were dissolved in $\mathrm{CDCl}_{3}$ and the spectra were recorded at $303 \mathrm{~K}$. Chemical shifts $(\delta)$ were expressed in ppm respect to the $\mathrm{CDCl}_{3}$ signals. Molecular weight and distribution were measured by GPC in a Waters HPLC equipped with a differential refraction index detector. The analyses were performed in THF at a flow rate of $0.8 \mathrm{~mL} / \mathrm{min}$ using a HR $4 \mathrm{E}$ column.

\subsection{Preparation of $\alpha$-tocopherol loaded Nanoparticles (TOC-NP)}

The preparation of $\alpha$-tocopherol loaded nanoparticles was as follows: $10 \mathrm{mg}$ of $\alpha$-tocopherol and $50 \mathrm{mg}$ of the corresponding copolymer were dissolved in $5 \mathrm{~mL}$ of acetone. The resulting solution was slowly droplet $(100 \mu \mathrm{L} / \mathrm{min})$ into $10.0 \mathrm{~mL}$ of an aqueous $\mathrm{HCl}$ solution $\mathrm{pH}$ 5.0. The resulting dispersion was gently stirred during 1 hour under reduced pressure to eliminate acetone residuals. Finally, the aqueous suspensions were lyophilized, rinsed with hexane at room temperature to eliminate non-encapsulated $\alpha$-tocopherol. The amount of encapsulated $\alpha$-tocopherol was determined dissolving the polymer samples in acetone, and analyzing the content of this substance by HPLC.

The loading-efficiency (DLE\%) as well as the drug content (DLC\%) were estimated using as follows:

$\begin{aligned} & \text { Encapsulation } \\ & \text { Eficience }(\%)\end{aligned}=\frac{\text { Amount of TOC in the NP }}{\text { Amount of TOC used in the preparation }} \times 100$

Encapsulation of $A T(\%)=\frac{\text { Amount of TOC in the NP }}{\text { mass of polymer }+ \text { TOC }}$

\subsection{Nanoparticles characterization}

Particles average diameter was determined by Dynamic Light Scattering (DLS) using a Horiba LB 550 equipment. The measurements were carried out at $23{ }^{\circ} \mathrm{C}$ in aqueous dilutions of the samples $(\approx 1 / 20)$ prepared using deionized water $(\sim 18 \mathrm{M} \Omega \mathrm{cm})$, in order to avoid particle - particle interactions, and multiple scattering effects, each dispersion plot corresponds to an average of 128 measurements acquired during 2 seconds. $\zeta$ potential was measured using a zeta potential analyzer Malvern Zetasizer Nano ZS. $\zeta$ potential was determined three times for each sample.

For TEM analysis, $2 \mu \mathrm{L}$ of the diluted samples $(0.1 \mathrm{mg} / \mathrm{mL})$ was spilled into a cupper grid Formvar ${ }^{\circledR}$ coated, and dried at room temperature during $24 \mathrm{~h}$, the images were obtained in a Jeol 1400 plus microscope.

\subsection{In vitro release of de $\alpha$-tocopherol}

In vitro release of TOC from TOC-NP's was studied based on a protocol published by Wang et al. ${ }^{[20]}$. Briefly, $4.0 \mathrm{~mL}$ of the $\alpha$-tocopherol loaded nanoparticles dispersed in PBS pH 7.4 (4 mg of TOC-PNP's/1 mL of buffer) were transferred to a dialysis bag (MWCO $12 \mathrm{kDa}$ ), and placed in $50.0 \mathrm{~mL}$ PBS pH 7.4 supplemented with SDS $5 \mathrm{wt} \%$ to guarantee sink conditions. At selected time intervals, $2 \mathrm{~mL}$ of the release medium (outside the dialysis bag) was extracted and analyzed by HPLC to determine the concentration of $\alpha$-tocopherol, and replace with equal volume of fresh releasing medium.

\section{7 In vitro antioxidant activity evaluation}

The antioxidant activity of TOC-PNP's was determined using 2,2'-azino-bis(3-ethylbenzothiazoline-6-sulfonic acid) (ABTS) based on methods previously reported ${ }^{[21,22]}$. 
Briefly, a stock solution of ABTS radical cation was prepared dissolving $20 \mathrm{mg}$ of ABTS in $10 \mathrm{~mL}$ of deionized water, and then $2.5 \mathrm{mg}$ of potassium persulfate $\mathrm{K}_{2} \mathrm{~S}_{2} \mathrm{O}_{8}$ was dissolved. The resulting solution was stored at room temperature during $16 \mathrm{~h}$ in a dark bottle.

Dilutions of ABTS with absorbance equal to $0.70 \pm 0.02$ at $740 \mathrm{~nm}$ containing different concentrations of the nanoparticles were prepared. The absorbance of ABTS ${ }^{+}$. was monitored at $740 \mathrm{~nm}$ each $60 \mathrm{~s}$ using a microplate spectrometer FluorStar omega. The radical scavenging activity of TOC-NP was estimated as the inhibition percentage as shown in Equation 3.

$$
\operatorname{Inhibition}(\%)=\frac{A_{0}-A_{t}}{A_{0}} \times 100
$$

Where $\mathrm{A}_{0}$ and $\mathrm{A}_{\mathrm{t}}$ correspond to the initial and stationary absorbance (at $60 \mathrm{~min}$ ), respectively. The trolox equivalent antioxidant capacity (TEAC) value represents the ratio between the slope of the plot inhibition (\%) vs concentration of TOC-NP under investigation, compared with the slope of this plot for $\mathrm{ABTS}^{+}$. scavenging by the water-soluble vitamin $\mathrm{E}$ analogue Trolox, used as an antioxidant standard.

\section{Results and Discussions}

\subsection{Synthesis of triblock copolymers PNIPAM-b-PCL-b- PNIPAM}

Amphiphilic triblock copolymers PNIPAM- $b$-PCL- $b$ PNIPAM were synthesized by using an activator regenerated by electron transfer (ARGET) process for atom transfer radical polymerization (ATRP). NIPAM was polymerized using a dibromide-ended polycaprolactone (Br-PCL-Br) as macroinitiator and $\mathrm{CuBr}_{2}$ / PMDETA as a catalyst, as shown in Scheme 1.

Two $\alpha, \omega$-dihydroxy-PCL samples with different $M_{n}$ values of 10 and $45 \mathrm{kDa}$ were transformed into Br-PCL-Br by reacting with an excess of BIBB. The reaction was assessed by ${ }^{1} \mathrm{HNMR}$; the anchorage of bromoisobutyryl groups was indicated by the absence of the signal at $3.62 \mathrm{ppm}$ of the hydroxymethylene terminal groups of PCL, and also by the presence of a new signal at $1.96 \mathrm{ppm}$ due to methyl groups of BIBB.

Triblock copolymers PNIPAM-b-PCL-b-PNIPAM containing PCL of 10 and $45 \mathrm{kDa}$ and PNIPAM were synthesized using the fee reagent molar ratios and reaction times listed in Table 1. The block copolymerization was confirmed by ${ }^{1} \mathrm{HNMR}$ and GPC. The complete signal assignation is presented in Figure 1. The average number molecular weight of the copolymers $\left(\mathrm{M}_{\mathrm{n}}\right)$, and the polymerization degree of $\operatorname{NIPAM}\left(X_{\text {NIPAM }}\right)$ relative to PCL were estimated from the ${ }^{1} \mathrm{HNMR}$, using equations showed below:

$$
\begin{aligned}
& X_{N I P A M}=\frac{I_{f}}{3} \times \frac{M_{n} P C L}{114} \\
& M_{n}=M_{n} P C L+\left(113.16 \times X_{N I P A M}\right)
\end{aligned}
$$

Where $\mathrm{I}_{\mathrm{f}}$ is the ratio of the intensity of signals at $1.6 \mathrm{ppm}$ that corresponds to methylene $\left(\mathrm{CH}_{3}\right)_{2}-\mathrm{C}$ groups of PNIPAM, and $2.40 \mathrm{ppm}$ assigned to $-\mathrm{CH}_{2}-$ of PCL.

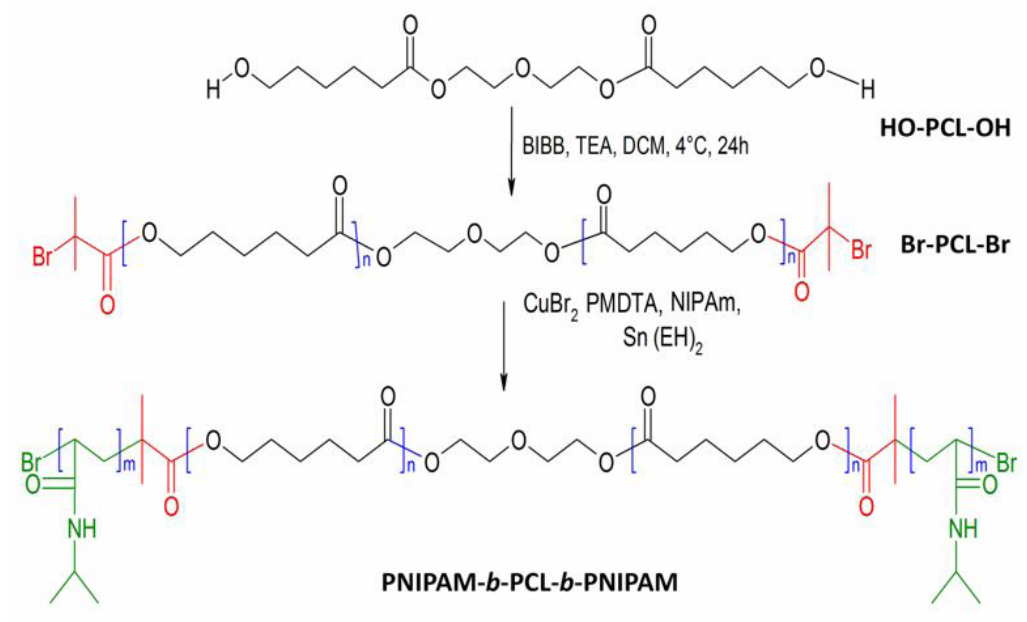

Scheme 1. Synthesis of Polycaprolactone ended in Bromide groups and its block copolymerization with N-isopropylacrylamide via ATRP.

Table 1. Molar ratio of the monomers in the fee and copolymers, Mn of the copolymers estimated by ${ }^{1} \mathrm{HNMR}$ and molecular weight dispersity obtained by GPC.

\begin{tabular}{ccccc}
\hline Sample & $\begin{array}{c}\text { Br-PCL-Br:NIPAM in } \\
\text { the feed }\end{array}$ & $\begin{array}{c}\text { Copolymers } \\
\text { Composition* }\end{array}$ & $\begin{array}{c}\mathbf{M}_{\mathbf{n}} \\
\text { (kDa) }\end{array}$ & PDI \\
\hline $27: 88: 27$ & $1: 246$ & $54: 88$ & 16.03 & 1.21 \\
$17: 88: 17$ & $1: 123$ & $34: 88$ & 13.90 & 1.32 \\
$108: 394: 108$ & $1: 320$ & $394: 216$ & 69.36 & 1.25 \\
\hline
\end{tabular}

*molar ratio of the monomers in the copolymers CL:NIPAM. 


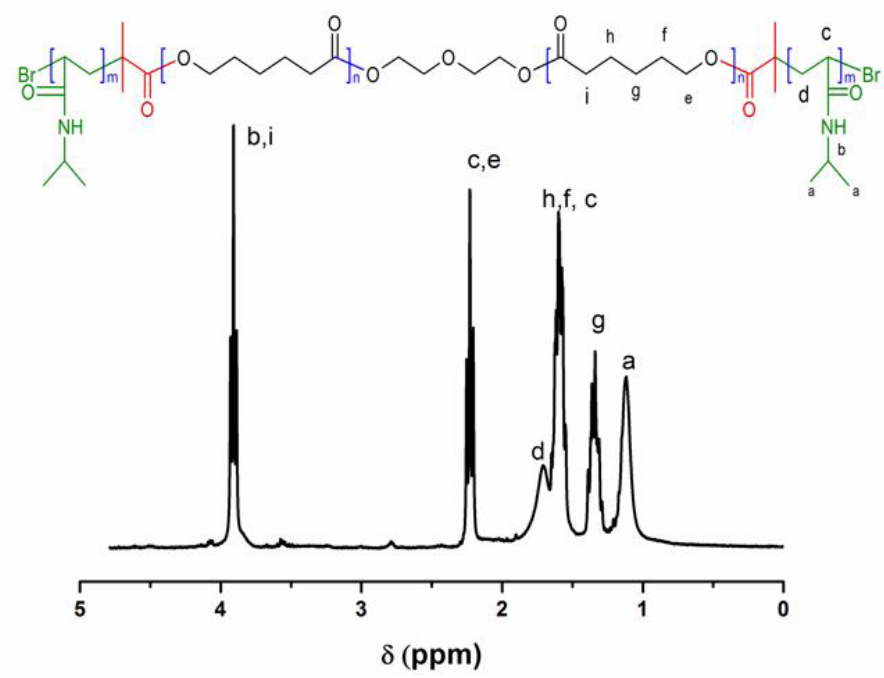

Figure 1. ${ }^{1} \mathrm{HNMR}$ spectra for copolymer 108:394:108 showing the signal assignation.

\subsection{Characterization of the nanoparticles}

In aqueous medium, amphiphilic block copolymers self-assemble by association of the hydrophobic blocks giving several types of nanoparticles. Although numerous morphologies have been reported, the most simple and investigated situation is the formation of hydrophobic cores and hydrophilic shells. Analogous to low molecular weight, amphiphilic block copolymers self-assemble forming polymer micelles, although PM's can also exhibits a dynamic character resembling micelles obtained from low molecular weight surfactants. PM's are often not dynamic depending on the hydrophobic/hydrophilic ratio and also the molecular weight of the copolymer. When the molecular weight of the hydrophilic block exceeds that of the hydrophobic block, the copolymer is easily dispersed in water and will self-assemble into small, relatively monodisperse micelles which are dynamic. However, as the molecular weight of the hydrophobic block approaches or exceeds the molecular weight of the hydrophilic block the polymer chains are insoluble limiting unimers exchange equilibrium that characterizes micellar dispersions ${ }^{[23]}$.

In this work, NP were obtained using amphiphilic block copolymers PNIPAM- $b$-PCL- $b$-PNIPAM as precursors at $\mathrm{pH} 5.0$ and $20^{\circ} \mathrm{C}$ at which PNIPAM displays hydrophilic behavior. For all the samples, even at concentration of the polymer lower than $1 \mathrm{mg} / \mathrm{L}$, and using pyrene as fluorescent probe, dissolution of the particles was not detected indicating that unimers exchange is quite slow, and therefore not observed under the experimental conditions. This behavior can be due to the fact the copolymer chains are poorly soluble in aqueous medium, as deduced from the composition of the samples presented in Table 2 where it is observed that the hydrophobic segment (PCL) exceeds the length of the hydrophilic ones.

The size of NP's obtained by nanoprecipitation was studied by DLS. Figure 2A-D shows the particle distribution and the corresponding TEM images as insets, the average diameter and dispersity index (PDI) values are summarized in Table 2. It is observed that the average particle diameter and its PDI depend on the composition of the copolymers.
Table 2. Average diameter of the particles measured by DLS and the corresponding $\zeta$ potential values.

\begin{tabular}{cccc}
\hline Sample & $\begin{array}{c}\text { Average } \\
\text { diameter }(\mathbf{n m})\end{array}$ & Polydispersity & $\begin{array}{c}\zeta \text { potential } \\
(\mathbf{m V})\end{array}$ \\
\hline $27: 88: 27$ & 281 & 0.14 & +5.5 \\
$17: 88: 17$ & 178 & 0.68 & +3.5 \\
$108: 394: 108$ & 44.4 & 0.07 & +10.5 \\
\hline
\end{tabular}

The smallest particles correspond to the copolymer containing the longest PCL block. Also, the largest PNIPAM segment leads to larger particles.

The relationship between the size of the particles and the composition of the block copolymers can be understood based on the mechanism for particle formation. It is that first individual molecules rapidly associate via nucleation, and growth until the particles have reached a size where further growth increases the free energy of the system ${ }^{[23]}$. Copolymer 108:394:108 is quite insoluble in water, therefore its chains aggregate at very low concentration, leading to the formation of small particles. TEM images indicate that the nanoparticles obtained at $20^{\circ} \mathrm{C}$ are spherical and exhibits a core-shell structure. For all the samples, primary particles smaller than $100 \mathrm{~nm}$ are forming aggregates.

Particle size distribution of PN of copolymer 108:394:108 prepared at $40{ }^{\circ} \mathrm{C}$ is shown in Figure 2D. Compared to the corresponding nanoparticles obtained at $20{ }^{\circ} \mathrm{C}$, the particles obtained at higher temperature exhibited a broader distribution, and also a significantly larger particle average size. TEM image (inset Figure 2D) indicates that the sample is composed by amorphous particles. This behavior obeys to the thermosensitive nature of PNIMAN, at $20^{\circ} \mathrm{C}$ it is hydrophilic and provides the particles stability.

The surface charge of the particles was determined by measuring its $\zeta$ potential, the corresponding values are listed in Table 2 . At all the composition the $\zeta$ potential was positive, which indicates that at the conditions at which the measurement was carried out, the PNIPAM segments are protonated. The results also indicate that $\zeta$ potential also depends on length of the hydrophilic segment. 
Figure 3A shows the temperature-dependent optical transmittance at $540 \mathrm{~nm}$ obtained for nanoparticles dispersions in the range of 20 to $40{ }^{\circ} \mathrm{C}$. It is observed that as the temperature increases, the transmittance of light decreases, which indicates that the turbidity of the samples increases, this behavior agrees with the lower critical solution temperature (c.a. $32^{\circ}$ ) of PNIPAM widely reported. These results probe that the nanoparticles are thermosensitive and also corroborate the previously describe core shell morphology. As a consequence of the thermosensitive behavior of TOC-NP endowed by the presence of PNIPAM, the solubility of the nanoparticles can be altered by increasing the temperature. According to Figure $3 \mathrm{~B}$, at $20^{\circ} \mathrm{C}$ the particles disperse well in water, but at $40^{\circ} \mathrm{C}$ the particles are become more compatible with an organic non-polar phase such as decane.

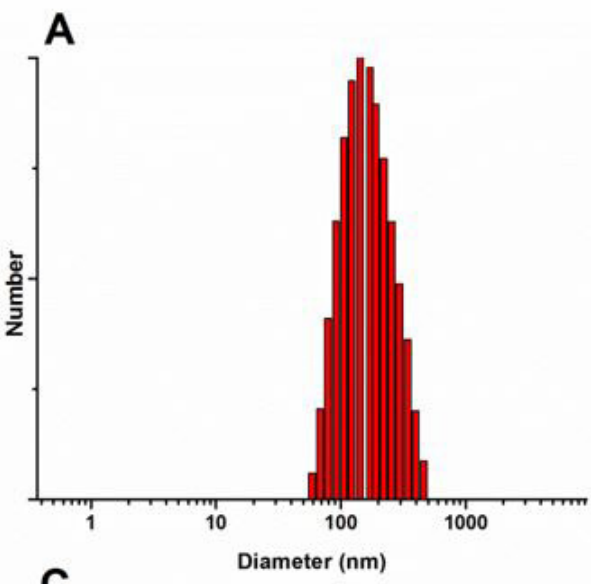

\section{B}
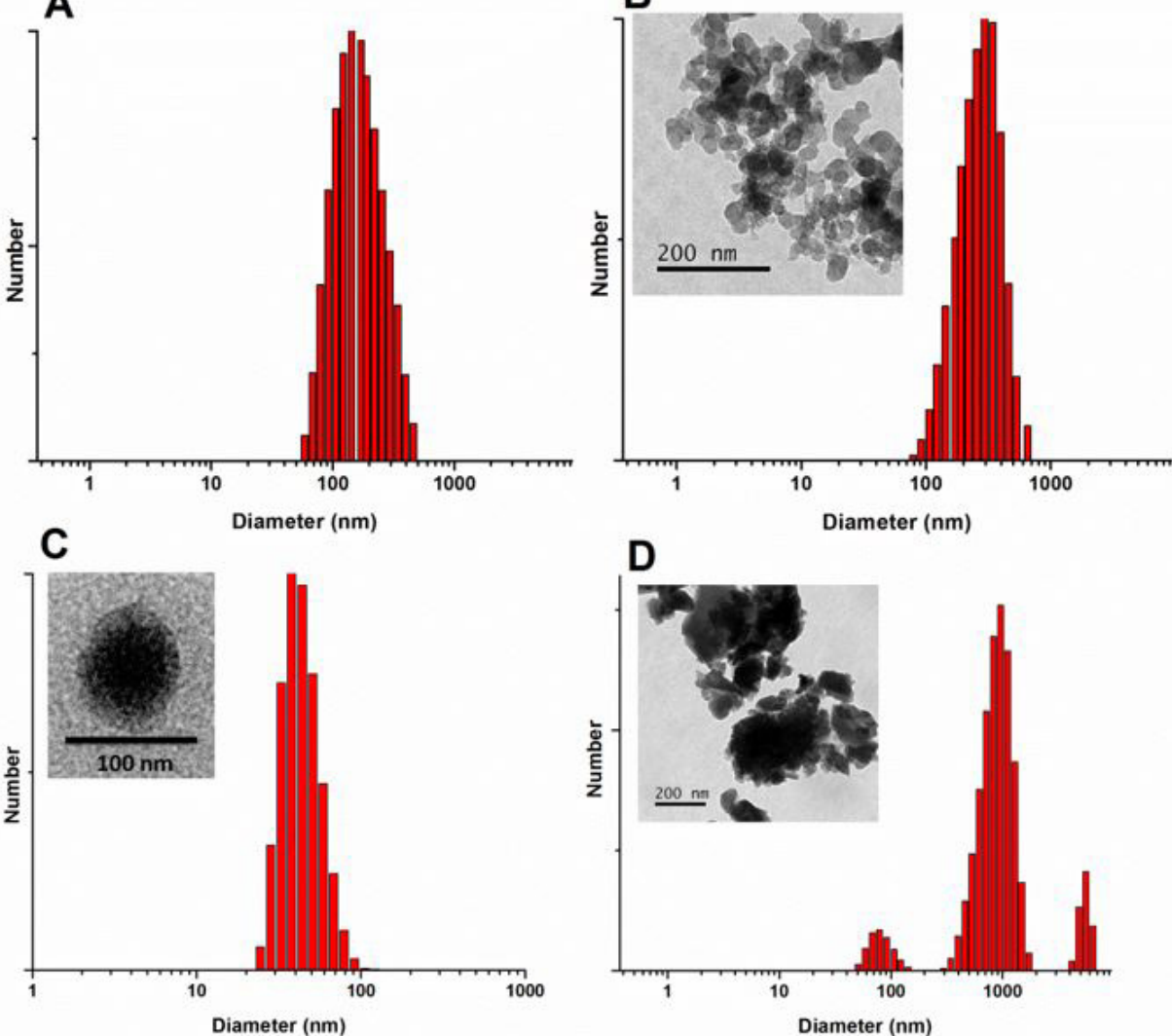

Figure 2. Particle size distribution obtained by DLS and the corresponding TEM image as inset obtained at $20{ }^{\circ} \mathrm{C}$ for copolymer (A) 17:88:17; (B) 27:88:27; and (C) 108:394:108; (D) corresponds to particles obtained from copolymer 108:394:108 at $40{ }^{\circ} \mathrm{C}$.
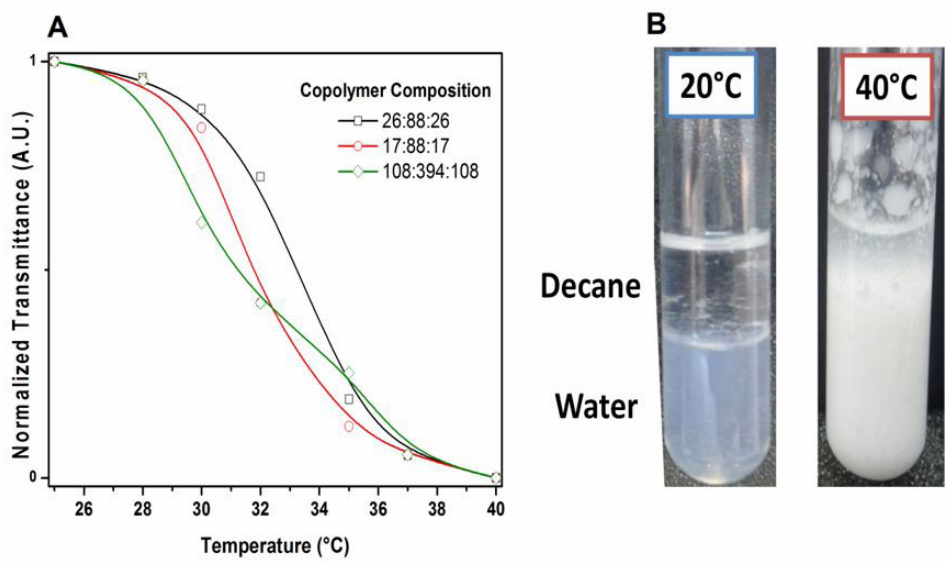

Figure 3. Thermosensitive behavior of TOC-NP. (A) optical transmittance of aqueous dispersions of the NP in the range of 20 to $40{ }^{\circ} \mathrm{C}$; (B) Photographs showing the behavior of aqueous dispersion of the NP at 20 and $40{ }^{\circ} \mathrm{C}$. 


\subsection{Thermal characterization of the nanoparticles}

DSC experiments were performed heating the samples from room temperature to $150^{\circ} \mathrm{C}$ at $20^{\circ} \mathrm{C} / \mathrm{min}$ to erase their thermal history and eliminate any volatile interfere. Then the samples were cooled at $10^{\circ} \mathrm{C} / \mathrm{min}$ to $-50{ }^{\circ} \mathrm{C}$, the $T \mathrm{c}$ was taken as the temperature corresponding to the maximum of the exothermic crystallization peak (Figure 4A, C). The melting temperature $T_{M}$ and the melting enthalpy were measure during a second heating at $10^{\circ} \mathrm{C} / \mathrm{min}$ up to $100{ }^{\circ} \mathrm{C}$ as the temperature corresponding to the minimum of the melting peak (Figure 4C, D), and the area under the peak, respectively.

Compared to bulk PCL, the melting temperature of PCL in NP is evidently low, which may be due to imperfections or reduction of the lamellar thickness of PCL due to the nanoconfinement ${ }^{[24,25]}$. It agrees with the decrease of crystallization temperature (Tc) of PCL in the nanoparticles compared to bulk PCL that characterizes crystallization in confined structures. Hamley et al. studied the crystallization of diblock copolymers composed by Polyethylene and either a rubbery or glassy segment. In the last case, the authors found that the presence of rigid walls significantly retards the crystallization process ${ }^{[26]}$.
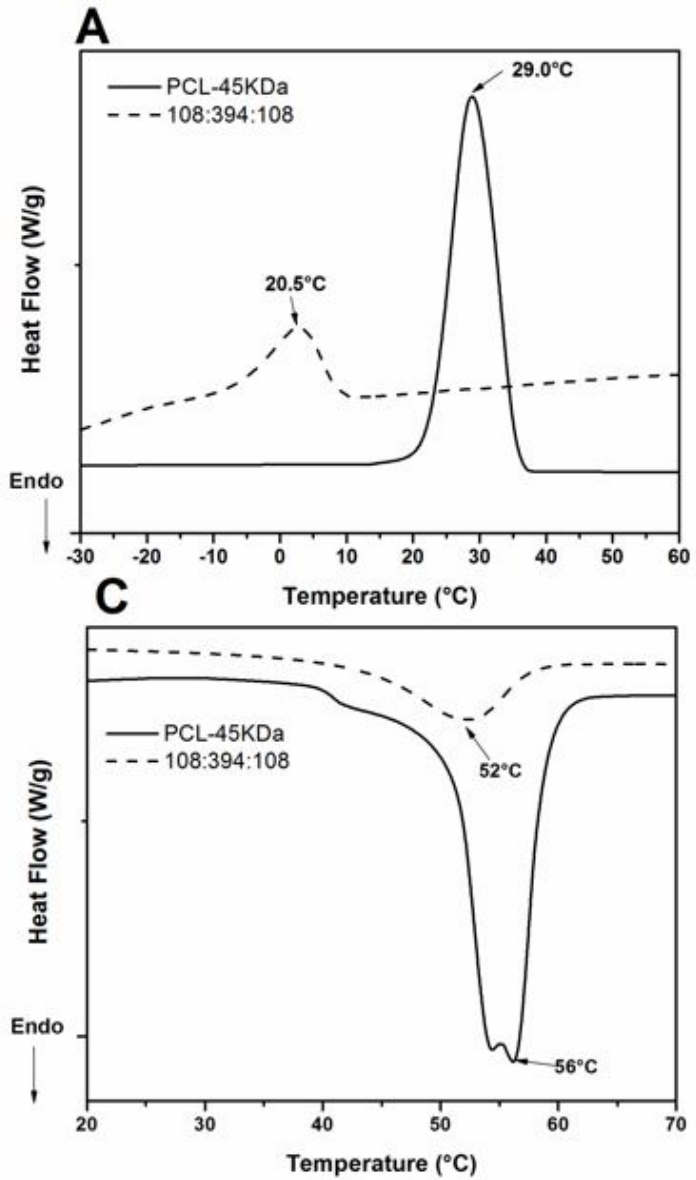

From Figures 4C, D, it is observed that the intensity of the melting peak of PCL in the NP's is minor compared with PCL homopolymer, indicating a lower crystallinity of the hydrophobic domains. The weight percentage of crystalline PCL in each one of the samples calculated from Equation 6 is listed in Table 3.

$$
\chi=\frac{\Delta H_{m}}{X_{P C L} \times \Delta H_{m}^{0}} \times 100
$$

where $\Delta H_{\mathrm{m}}$ is the apparent heat of fusion per gram of the nanoparticles, $X_{P C L}$ is the corresponding weight fraction of PCL obtained from the sample compositions listed in Table 1. $\Delta H_{\mathrm{m}}{ }^{\circ}$ is the thermodynamic heat of fusion per gram of completely crystalline PCL and was assumed to be $135.31 \mathrm{~J} / \mathrm{g}^{[27]}$.

\subsection{Encapsulation of $\alpha$-tocopherol and in vitro release}

The loading-efficiency (TLE) and the TOC content (TLC) determined by Equations 1 and 2, respectively, are summarized in Table 4. It is observed that the nanoparticles obtained from the copolymer with the longest PCL segment presents larger TOC and TLC values. TOC-NPs were prepared
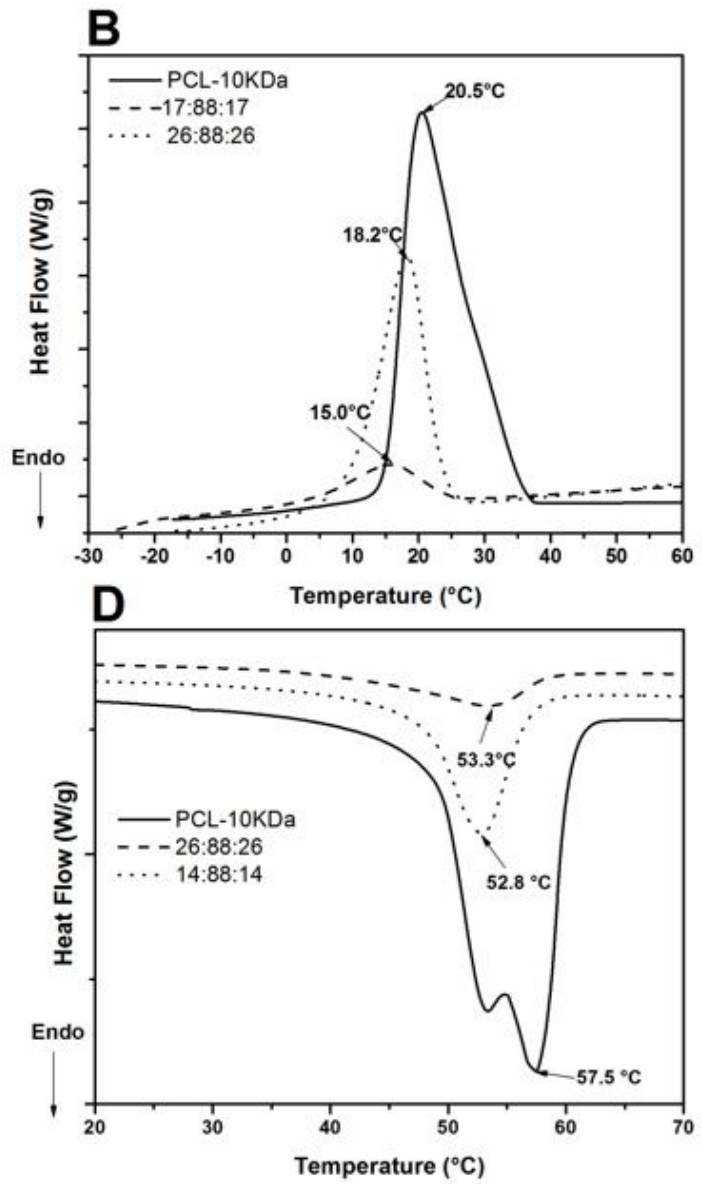

Figure 4. DSC thermograms obtained for the nanoparticles and PCL bulk (A, B) cooling and (C, D) heating. 
Table 3. DSC characterization of the samples and their corresponding PCL precursors.

\begin{tabular}{cccccc}
\hline Sample & $\begin{array}{c}\Delta \mathbf{H}_{\mathbf{m}} \\
\mathbf{J} / \mathbf{g}\end{array}$ & $\begin{array}{c}\mathbf{T}_{\mathbf{m}} \\
{ }^{\circ} \mathbf{C}\end{array}$ & $\begin{array}{c}\mathbf{T}_{\mathbf{c}} \\
{ }^{\circ} \mathbf{C}\end{array}$ & $\begin{array}{c}\boldsymbol{X}_{P C L} \\
\mathbf{w t}_{\mathbf{0}}\end{array}$ & 50.0 \\
\hline PCL-10 & 67.6 & 57.5 & 20.5 & 1 & 0.61 \\
26:88:26 & 9.08 & 53.3 & 52.8 & 15.0 & 0.72 \\
17:88:17 & 22.89 & 56.1 & 29.0 & 11.0 \\
PCL-45 & 68.0 & 52.0 & 20.5 & 50.3 \\
108:384:108 & 14.7 & 17.0 & 0.64 \\
\hline
\end{tabular}

Table 4. Encapsulation of TOC and antioxidant properties.

\begin{tabular}{|c|c|c|c|c|}
\hline \multirow[b]{2}{*}{ Sample } & \multicolumn{2}{|c|}{ TOC encapsulation } & \multicolumn{2}{|c|}{ Antioxidant Properties } \\
\hline & Loading (\%) & Efficiency (\%) & $\begin{array}{c}\text { IC50 } \\
(\mathrm{mg} \text { TOC-NP/L) }\end{array}$ & TEAC* \\
\hline $26: 88: 26$ & 8.1 & 40.5 & $545 \pm 54$ & $0.69 \pm 0.05$ \\
\hline $17: 88: 17$ & 8.5 & 42.5 & $472 \pm 21$ & $0.71 \pm 0.01$ \\
\hline $108: 384: 108$ & 10.1 & 50.5 & $406 \pm 18$ & $1.15 \pm 0.19$ \\
\hline
\end{tabular}

*Trolox Equivalent Antioxidant capacity expressed as mmol of trolox/weight (g) of TOC-NP.

by nanoprecipitation, both copolymer and tocopherol are dissolved in acetone, and then added dropwise into an aqueous solution at $\mathrm{pH}$ 5.0. Under these conditions, the encapsulation of TOC is due to its partition between the aqueous phase, and the nucleus of the forming particles. The low solubility of TOC in water facilitates its encapsulation in the hydrophobic PCL domains generated on the self-assembly of the copolymers. In a previous research, it was found that hydrophobicity of cores of micelles obtained from block copolymers containing PCL, increases with me molecular weight of PCL. Assuming the same tendency, the larger values of encapsulation parameters obtained for copolymer 108:394:108 are due to a more hydrophobic particles core which summed to its low crystallinity enables the encapsulation of TOC. Nanoparticles based on PNIPAM- $b$-PCL- $b$-PNIPAM allowed obtaining larger encapsulation percentages than the values early reported for polymer nanoparticles obtained from PCL homopolymer ${ }^{[28]}$.

Release profiles of TOC from TOC-NP under sink conditions are shown in Figure 5. The plots show that these formulations exhibit a controlled release along $140 \mathrm{~h}$. For each sample, the release profiles exhibits two different regions, an initial burst during the first $20 \mathrm{~h}$, and then a minor release rate. After $150 \mathrm{~h}$, the cumulative release was larger than $70 \%$ for all the formulations, but only NP obtained from copolymer 108:384:108 showed a cumulative release close to $100 \%$.

\subsection{In vitro antioxidant activity}

The antioxidant activity of TOC-NP's was tested using the trolox equivalent antioxidant capacity (TEAC) ${ }^{[21]}$. In this test, the relative capacity of encapsulated TOC to scavenge the $\mathrm{ABTS}^{+}$. radical - cation is compared to Trolox which is a hydrosoluble compound structurally analogous, and used as a standard. $\mathrm{ABTS}^{+}$. radical cation in aqueous solution and in absence of light is stable for several hours. The strong absorption of this species at $732 \mathrm{~nm}$ permits sensing it residual concentration as it reacts with TOC. A typical plot of $\mathrm{ABTS}^{+}$. inhibition percentage as function of time at different concentrations of TOC-NP is shown Figure 6A the

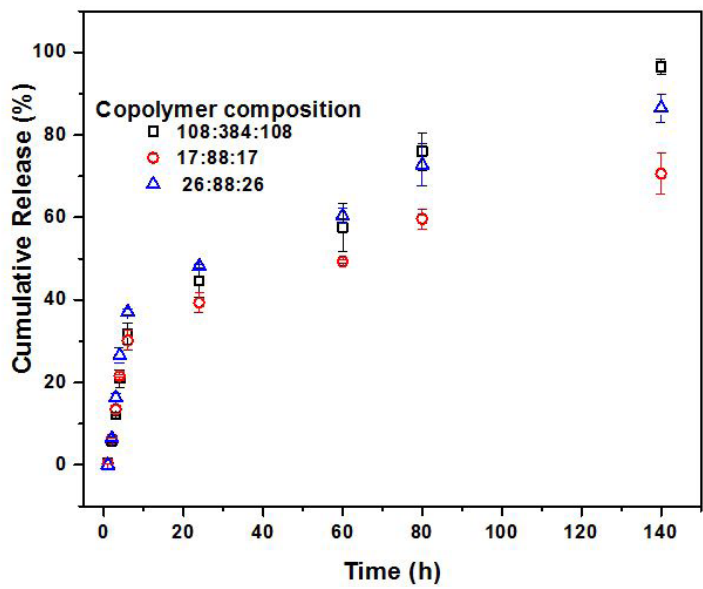

Figure 5. Release profiles of TOC from TOC-NP measured at room temperature under sink conditions.

inhibition at each concentration was taken at $60 \mathrm{~min}$, at that time we obtained a better data correlation.

The concentration of TOC-NP necessary to inhibit $50 \%$ of ABTS species was interpolated from the plots of inhibition percentage vs concentration. The corresponding values are listed in Table 4, the IC50 for all the samples was in the range of 400- $600 \mathrm{mg}$ of TOC-NP/L. The antioxidant activity measurements of AT-NP dispersions, expressed as Trolox equivalent antioxidant capacity (TEAC) are presented in Table 4.

TOC is known to be a lipophilic antioxidant with limited solubility in water. However, our results indicate that TOC-NP exhibits antioxidant properties in aqueous medium. Presumably, the small size of the particles and therefore their high surface area enables encapsulated TOC to react with $\mathrm{ABTS}^{+}$. Two phenomena could account for the antioxidant properties of TOC-NP; first, free radicals could diffuse through the nanoparticles taking advantage of the low crystallinity of PCL hydrophobic domains, and also the surface characteristics of the particles promotes a fast 

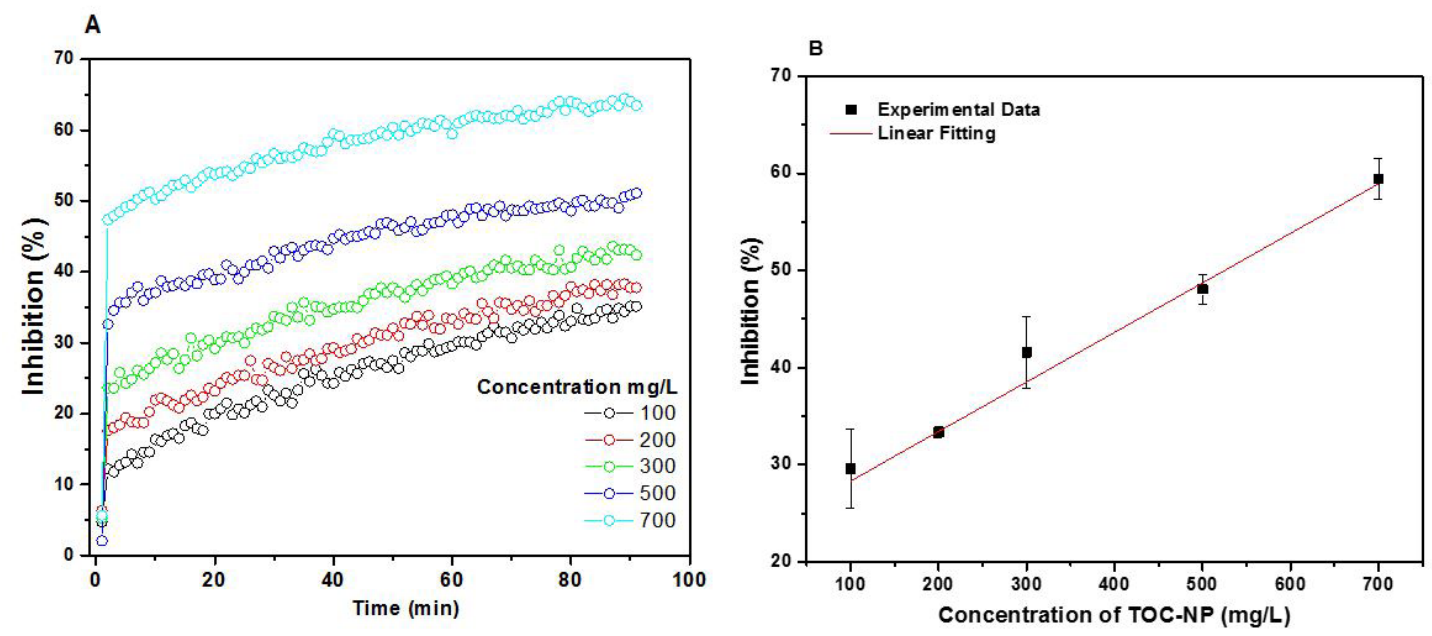

Figure 6. (A) Radical scavenging activity of TOC-NP expressed as ABTS inhibition percentage; (B) typical plot of inhibition (\%) as function of the concentration of TOC-NPs.

migration of TOC to the aqueous phase. Slight differences among the antioxidant capacities obtained for the evaluated formulations agrees with their corresponding content of TOC.

\section{Conclusions}

$\alpha$ - Tocopherol loaded nanoparticles were prepared by nanoprecipitation using amphiphilic triblock copolymers PNIPAM-b-PCL-b-PNIPAM as precursors. The nanoparticles presented average diameter smaller than $281 \mathrm{~nm}$, were positively charged and exhibited thermosensitivity. TOC-NP showed controlled released of TOC was achieved along $140 \mathrm{~h}$, and radical scavenging activity in aqueous dispersion.

\section{References}

1. Bramley, P. M., Elmadfa, I., Kafatos, A., Kelly, F. J., Manios, Y., Roxborough, H. E., Schuch, W., Sheehy, P. J. A., \& Wagner, K.-H. (2000). Vitamin E. Journal of the Science of Food and Agriculture, 80(7), 913-938. http://dx.doi.org/10.1002/(SICI)10970010(20000515)80:7<913::AID-JSFA600>3.0.CO;2-3.

2. Farias, M. C., Moura, M. L., Andrade, L., \& Leão, M. H. (2007). Encapsulation of the alpha-tocopherol in a glassy food model matrix. Materials Research, 10(1), 57-62. http:// dx.doi.org/10.1590/S1516-14392007000100013.

3. Hategekimana, J., Masamba, K. G., Ma, J., \& Zhong, F. (2015). Encapsulation of vitamin E: effect of physicochemical properties of wall material on retention and stability. Carbohydrate Polymers, 124(1), 172-179. PMid:25839808. http://dx.doi. org/10.1016/j.carbpol.2015.01.060.

4. Trombino, S., Cassano, R., Muzzalupo, R., Pingitore, A., Cione, E., \& Picci, N. (2009). Stearyl ferulate-based solid lipid nanoparticles for the encapsulation and stabilization of $\beta$-carotene and $\alpha$-tocopherol. Colloids and Surfaces. B, Biointerfaces, 72(2), 181-187. PMid:19410436. http://dx.doi. org/10.1016/j.colsurfb.2009.03.032.

5. Duclairoir, C., Orecchioni, A., Depraetere, P., \& Nakache, E. (2002). $\alpha$-Tocopherol encapsulation and in vitro release from wheat gliadin nanoparticles. Journal of Microencapsulation, 19(1), 53-60. PMid:11811759. http://dx.doi.org/10.1080/02652040110055207.
6. Quiñones, J. P., Gothelf, K. V., Kjems, J., Yang, C., Caballero, A. M. H., Schmidt, C., \& Covas, C. P. (2013). Self-assembled nanoparticles of modified-chitosan conjugates for the sustained release of dl- $\alpha$-tocopherol. Carbohydrate Polymers, 92(1), 856-864. PMid:23218376. http://dx.doi.org/10.1016/j. carbpol.2012.10.005.

7. Luo, Y., Zhang, B., Whent, M., Yu, L., \& Wang, Q. (2011). Preparation and characterization of zein/chitosan complex for encapsulation of $\alpha$-tocopherol, and its in vitro controlled release study. Colloids and Surfaces. B, Biointerfaces, 85(2), 145-152. PMid:21440424. http://dx.doi.org/10.1016/j. colsurfb.2011.02.020.

8. Kumari, A., Yadav, S. K., \& Yadav, S. C. (2010). Biodegradable polymeric nanoparticles based drug delivery systems. Colloids and Surfaces. B, Biointerfaces, 75(1), 1-18. PMid:19782542. http://dx.doi.org/10.1016/j.colsurfb.2009.09.001.

9. Rao, J. P., \& Geckeler, K. E. (2011). Polymer nanoparticles: preparation techniques and size-control parameters. Progress in Polymer Science, 36(7), 887-913. http://dx.doi.org/10.1016/j. progpolymsci.2011.01.001.

10. Kataoka, K., Harada, A., \& Nagasaki, Y. (2001). Block copolymer micelles for drug delivery: design, characterization and biological significance. Advanced Drug Delivery Reviews, 47(1), 113-131. PMid:11251249. http://dx.doi.org/10.1016/ S0169-409X(00)00124-1.

11. Yoon, H.-J., \& Jang, W.-D. (2010). Polymeric supramolecular systems for drug delivery. Journal of Materials Chemistry, 20(2), 211-222. http://dx.doi.org/10.1039/B910948J.

12. Sierra-Martin, B., Retama, J. R., Laurenti, M., Fernández Barbero, A., \& López Cabarcos, E. (2014). Structure and polymer dynamics within PNIPAM-based microgel particles. Advances in Colloid and Interface Science, 205(0), 113-123. PMid:24275613. http://dx.doi.org/10.1016/j.cis.2013.11.001.

13. Pintauer, T., \& Matyjaszewski, K. (2008). Atom transfer radical addition and polymerization reactions catalyzed by ppm amounts of copper complexes. Chemical Society Reviews, 37(6), 1087-1097. PMid:18497922. http://dx.doi.org/10.1039/ b714578k.

14. Hutmacher, D. W., Schantz, T., Zein, I., Ng, K. W., Teoh, S. H., \& Tan, K. C. (2001). Mechanical properties and cell cultural response of polycaprolactone scaffolds designed and fabricated via fused deposition modeling. Journal of Biomedical 
Materials Research, 55(2), 203-216. PMid:11255172. http:// dx.doi.org/10.1002/1097-4636(200105)55:2<203::AIDJBM1007>3.0.CO;2-7.

15. English, J., \& Perrin, D. (1998). Polycaprolactone. In A. Domb, J. Kost \& D. Wiseman, Handbook of biodegradable polymers (pp. 63-76). Amsterdam: CRC Press.

16. Nair, L. S., \& Laurencin, C. T. (2007). Biodegradable polymers as biomaterials. Progress in Polymer Science, 32(8-9), 762798. http://dx.doi.org/10.1016/j.progpolymsci.2007.05.017.

17. Peña A., Gutierrez S., Villamil J., Agudelo N. \& Perez L.D. (2015). Policaprolactone/polyvinylpyrrolidone/siloxane hybrid materials: synthesis and in vitro delivery of diclofenac and biocompatibity with periodontal ligament fibroblasts. Materials Engineering and Science: C, 58(1), 60-9. http:// dx.doi.org/10.1016/j.msec.2015.08.007.

18. Alarcon, C. H., Pennadam, S., \& Alexander, C. (2005). Stimuli responsive polymers for biomedical applications. Chemical Society Reviews, 34(3), 276-285. PMid:15726163. http://dx.doi. org/10.1039/B406727D.

19. Diaz, I. L., \& Perez, L. D. (2015). Synthesis and micellization properties of triblock copolymers PDMAEMA-b-PCL-bPDMAEMA and their applications in the fabrication of amphotericin B-loaded nanocontainers. Colloid \& Polymer Science, 293(3), 913-923. http://dx.doi.org/10.1007/s00396014-3478-3.

20. Wang, C.-H., Wang, W.-T., \& Hsiue, G.-H. (2009). Development of polyion complex micelles for encapsulating and delivering amphotericin B. Biomaterials, 30(19), 3352-3358. PMid:19299011. http://dx.doi.org/10.1016/j.biomaterials.2009.02.041.

21. Re, R., Pellegrini, N., Proteggente, A., Pannala, A., Yang, M., \& Rice-Evans, C. (1999). Antioxidant activity applying an improved ABTS radical cation decolorization assay. Free Radical Biology \& Medicine, 26(9-10), 1231-1237. PMid:10381194. http://dx.doi.org/10.1016/S0891-5849(98)00315-3.
22. Thaipong, K., Boonprakob, U., Crosby, K., Cisneros-Zevallos, L., \& Hawkins Byrne, D. (2006). Comparison of ABTS, DPPH, FRAP, and ORAC assays for estimating antioxidant activity from guava fruit extracts. Journal of Food Composition and Analysis, 19(6-7), 669-675. http://dx.doi.org/10.1016/j. jfca.2006.01.003.

23. Nicolai, T., Colombani, O., \& Chassenieux, C. (2010). Dynamic polymeric micelles versus frozen nanoparticles formed by block copolymers. Soft Matter, 6(14), 3111-3118. http://dx.doi. org/10.1039/b925666k.

24. Huyskens, P., Groeninckx, G., \& Vandevyvere, P. (1990). What rules the melting point of semi-crystalline polymers? Bulletin des Sociétés Chimiques Belges, 99(11-12), 1011-1017. http:// dx.doi.org/10.1002/bscb.19900991120.

25. Feng, S., Chen, Y., Meng, C., Mai, B., Wu, Q., Gao, H., Liang, G., \& Zhu, F. (2015). Study on the condensed state physics of poly ( $\varepsilon$-caprolactone) nano-aggregates in aqueous dispersions. Journal of Colloid and Interface Science, 450(0), 264-271. PMid:25823730. http://dx.doi.org/10.1016/j.jcis.2015.03.029.

26. Hamley, I. W., Fairclough, J. P. A., Bates, F. S., \& Ryan, A. J. (1998). Crystallization thermodynamics and kinetics in semicrystalline diblock copolymers. Polymer, 39(6-7), 14291437. http://dx.doi.org/10.1016/S0032-3861(97)00409-6.

27. Jiang, S., Ji, X., An, L., \& Jiang, B. (2001). Crystallization behavior of PCL in hybrid confined environment. Polymer, 42(8), 3901-3907. http://dx.doi.org/10.1016/S0032-3861(00)00565-6.

28. Byun, Y., Hwang, J. B., Bang, S. H., Darby, D., Cooksey, K., \& Dawson, P. L. (2011). Formulation and characterization of $\alpha$-tocopherol loaded poly e $\{$ open $\}$-caprolactone (PCL) nanoparticles. LWT - Food Science and Technology (Campinas), 44(1), 24-28. http://dx.doi.org/10.1016/j.1wt.2010.06.032.

Received: Aug. 14, 2015

Revised: Feb. 27, 2016

Accepted: Mar. 15, 2016 